\title{
PREVALENCE AND PATHOLOGY OF ABOMASAL ABNORMALITIES IN SHEEP IN SOUTHERN IRAN
}

\author{
A. KHODAKARAM-TAFTI ${ }^{1}$, A. HAJIMOHAMMADI ${ }^{2} \&$ F. $^{\text {AMIRI }}{ }^{1}$ \\ ${ }^{1}$ Department of Pathology, ${ }^{2}$ Department of Clinical Studies; \\ School of Veterinary Medicine, Shiraz University, Shiraz, Iran
}

\section{Summary}

Khodakaram-Tafti, A., A. Hajimohammadi \& F. Amiri, 2015. Prevalence and pathology of abomasal abnormalities in sheep in southern Iran. Bulg. J. Vet. Med., 18, № 3, 270-276.

\begin{abstract}
Abomasal abnormalities impose economic constraints on sheep production, most of which are subclinical and cannot be easily detected by routine clinical examination. In this survey, morphopathological lesions of 100 abomasa of sheep slaughtered in Fars Province, southern Iran were studied from spring to autumn of 2011. Grossly, raised pale to whitish nodular areas to irregularly thickened mucosa, different types of erosions or ulcers, phytotrichobezoars, and serosal cysts of Cysticercus tenuicollis were seen. Histopathologic examination revealed ostertagiasis $(79 \%)$, erosive-ulcerative abomasitis (75\%), eosinophilic abomasitis (14\%), Cysticercus tenuicollis cysts on the serosal surface $(9 \%)$, chronic hypertrophic abomasitis $(4 \%)$, coccidiosis $(3 \%)$ and submucosal granulomatous abomasitis (1\%). Microscopic features of the coccidial schizonts were consistent with previous descriptions of Eimeria (Globidium) gilruthi. Based on the results, it could be concluded that ostertagiosis was the most common abnormality in the abomasum of the sheep that can cause important economical losses. In addition, abomasal coccidiosis was reported for the first time and further research is required to clarify the pathogenesis and its epidemiologic importance in sheep.
\end{abstract}

Key words: abomasum, coccidiosis, morphopathological abnormalities, ostertagiosis, sheep

\section{INTRODUCTION}

Small ruminants play an important socioeconomic role within traditional farming systems in many developed and developing countries. Sheep are an important source of high quality food products such as meat and milk. Gastrointestinal diseases impose severe economic constraints on sheep production. Consistent with the physiological role and activities of abomasum, abomasal disorders and lesions can cause major disruptions in the normal functioning of the organ (Radostits et al., 2007). Abomasal ulcers are an important cause of indigestion in ruminants, occurring in several forms with different clinical signs (Whitlock, 1980; Braun et al., 1991). Causes of abomasal ulcers are complex and often obscure. Types of stress reported to be associated with this condition are environmental, nutritional, 
physical, genetic, hyperacidity, lactic acidosis, and coarse rations (Cebra et al., 2003; Blowey, 2004, Farshid et al., 2006; Mostaghni et al., 2008). The incidence was the highest in dairy cows during the summer months when the animals were grazing on pasture (Radostits et al., 2007). Sheep have numerous abomasal parasites. Losses occur due to subclinical disease, mortality, reduced production, decreased weight, decreased fertility and milk yield (Gross et al. 1999; Gelberg, 2011). Fars province of Iran is one of the most important sheep raising areas of the country. There were some observations in sheep flocks with subclinical diseases such as indigestion, weight loss, reduced production and mortalities. Since abattoir survey is a reliable and more accurate way to diagnose the abomasal lesions and disorders, this study was undertaken from spring to autumn of 2011 to describe the prevalence, gross and histopathological lesions of abomasum in the sheep in Fars province, southern Iran.

\section{MATERIALS AND METHODS}

Gross and histopathologic lesions of the abomasum were studied in 100 mixed breed, Iranian fat tailed sheep, regularly slaughtered in Fars province, southern Iran from spring to autumn of 2011. All animals had grazed on ranges around the city. They were also supplementeed with 0.5 to $1 \mathrm{~kg}$ of a locally made concentrate containing barley and wheat on a daily basis. Grossly, the type, number, location and characterisitics of any abnormalities including nodules, haemorrhages, erosions or ulcers, foreign bodies and parasites were observed and recorded. For histopathological examination, tissue samples were taken from different parts including fundic, body and pyloric regions of abo- masa of 100 cases. The tissue specimens, were fixed in $10 \%$ buffered formalin, processed and embedded in paraffin, sections of $5 \mu \mathrm{m}$ thickness were cut and stained with haematoxylin-eosin (H\&E) and studied microscopically. Each abomasal ulcer was classified to four types including erosions of abomasal mucosa as type 1 , bleeding ulcers as type 2, perforated ulcers with local peritonitis as type 3 , and perforated ulcers with generalised peritonitis as type 4 (Whitlock, 1980). Also, type 1 ulcers were divided into four subtypes including 1a, 1b, 1c, and 1d as described by Braun et al. (1991). Reddish erosion with minimal mucosal defect was defined as subtype 1a; dark red erosion combined with local haemorrhage as subtype $1 \mathrm{~b}$; craterous ulcers with typical bulged margins as subtype 1c and deep ulcers with radial wrinkles which came from different directions and converged at a central point as subtype $1 \mathrm{~d}$.

\section{RESULTS}

\section{Gross findings}

In more than 70 percent of examined abomasa, the content was watery, seldom with foul smelling. In these abomasa, the mucosa had different patterns as multifocal to diffuse thickening and corrugation, focal to multifocal thickening and presence of scattered pale to whitish small nodules in the mucosa (Fig. 1). Rarely, a number of tiny brown and threadlike worms, Teladorsagia (Ostertagia) circumcincta, were seen on the mucosa. Concurrent ulcers associated with small nodules of Ostertagia were observed in $61 \%$ of abomasa. The most important types and frequency of pathologic lesions of abomasa are shown in Table 1.

The prevalence of abomasal phytotrichobezoars was 12 percent. These balls 
Prevalence and pathology of abomasal abnormalities in sheep in southern Iran

Table 1. Type and frequency of pathologic lesions of abomasum in slaughtered sheep $(n=100)$

\begin{tabular}{lcc}
\hline Pathologic lesions & Number & Percentage(\%) \\
\hline Erosions and ulcers & 75 & 75 \\
Phytotrichobezoars & 12 & 12 \\
Chronic hypertrophic abomasitis & 4 & 4 \\
Osteratagiosis & 79 & 79 \\
Cysticercus tenuicollis cysts & 9 & 9 \\
Abomasal coccidiosis & 3 & 3 \\
\hline
\end{tabular}

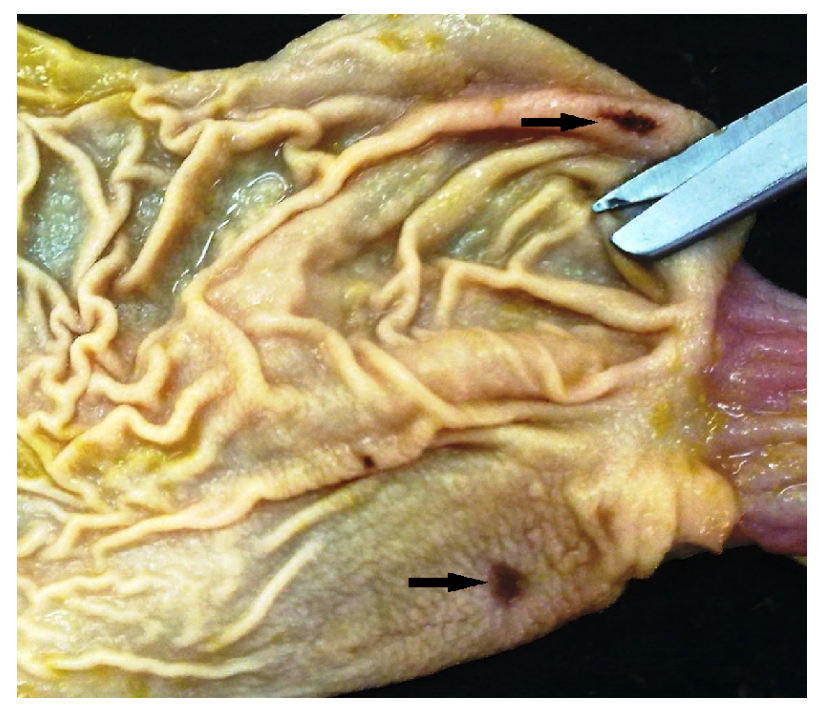

Fig. 1. Sheep abomasum. Different type 1 ulcers (arrows) associated with numerous whitish nodules of ostertagiosis in the mucosa.

were oval or round usually with dark brown to black in colour. The coincidence of abomasal ulcers and phytotrichobezoars was observed in 9 percent of them.

The prevalence of abomasal ulcers was 75 percent. Based on gross appearances, erosion with minimal mucosal defect (subtype 1a) was seen in 66 percent of abomasa. This lesion was often reddish-violet or greenish-brown. Subtype 1b ulcer or deeper erosion combined with local haemorrhage was observed in 38 percent, this type of ulcer appeared as sharply defined, dark red to black spots, which had a punched-out appearance; the center of this lesion was always clearly depressed. Subtype 1c ulcers or craters with a superficial coating of detritus, fibrin, or inflammatory products were seen in 18 percent of abomasa. The centre of this lesion was depressed, and the margins usually formed a typical bulge (Fig. 1). The prevalence of subtype $1 \mathrm{~d}$ ulcer was 7 percent. It occurred mainly on the gastric folds and had radial wrinkles which came from different directions and converged at a central point. Type 2 ulcer was observed only in one percent of animals. The topographical distribution of the various subtypes of ulcers showed that they were 
mostly located in abomasal pylori and bodies. In 9 percent of the abomasa, Cysticercus tenuicollis cysts were found attached on the serosal surface. The cysts were full of clear fluid with bladder-like appearance and contained a single whitish scolex.

\section{Histopathological findings}

The histopathologic lesions and their prevalence found in the abomasa included osteratagiosis $(79 \%)$, erosive-ulcerative abomasitis (75\%), eosinophilic abomasitis (14\%), chronic hypertrophic abomasitis (4\%), coccidiosis (3\%) and submucosal granulomatous abomasitis (1\%). In osteratagiosis, thickening of the mucosa, dilation of glands associated with prominent hyperplasia of epithelial and mucus cells, presence of Ostertagia larvae within the affected glands and mucosal nodules and infiltration and aggregation of lymphocytes, plasma cells and eosinophils were seen (Fig. 2).

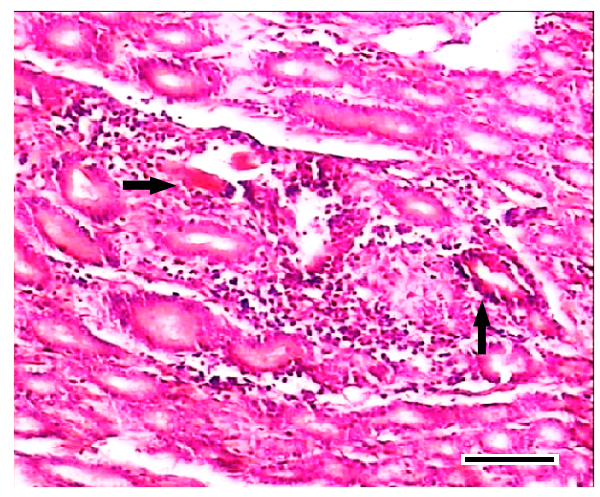

Fig. 2. Sheep abomasum. Ostertagiosis. Presence of the Ostertagia larvae within the affected glands associated with aggregation of lymphocytes, plasma cells and eosinophils around the affected glands in the mucosa (arrows). $B a r=1 \mathrm{~cm}$.

Erosive-ulcerative abomasitis was characterised by acute to subacute degenera- tion and necrosis of the superficial epithelial cells associated with congestion and oedema of the mucosa. In most ulcers, neutrophilic to mononuclear inflammatory reaction was seen peripheral to necrotic tissue. Eosinophilic abomasitis was diagnosed on basis of infiltration and aggregation of eosinophils in the mucosa without any presence of parasite larvae. In chronic hypertrophic abomasitis, proliferation of mucosal glands and infiltration of mononuclear inflammatory cells especially lymphocytes was observed.

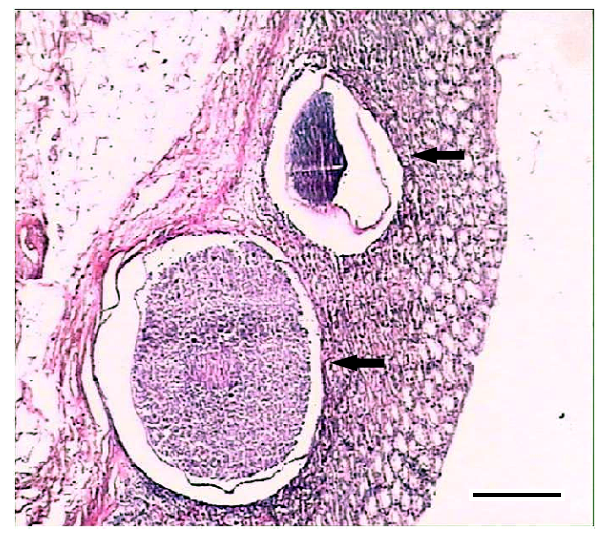

Fig. 3. Sheep abomasum. Coccidiosis. Coccidial schizonts (arrows) are observed in the mucosa. $\mathrm{Bar}=1 \mathrm{~cm}$.

In three percent of examined abomasa, a small number of intact or degenerated giant schizonts of coccidia were observed in the mucosa, mostly in lacteals (Fig. 3). They were not extended into the submucosa. The schizonts were round to ovoid, thin or thick walled and contained many merozoites (Fig. 4). Neither sexual stages nor oocysts were seen in the affected mucosa. In one abomasum, a relatively large granulomatous lesion with multiple giant cells was diagnosed in the submucosa. 


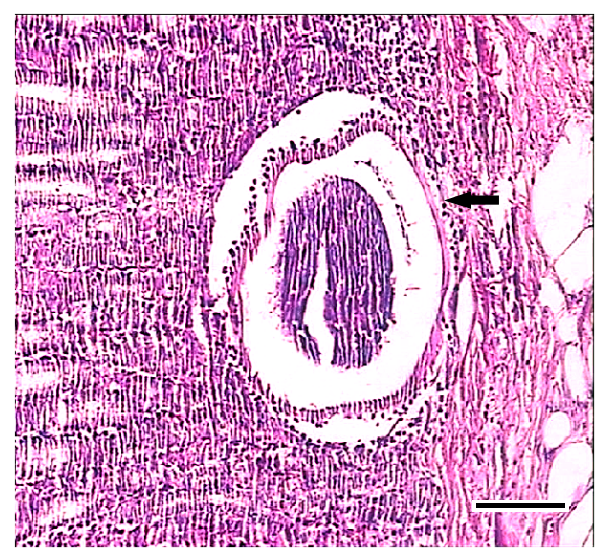

Fig. 4. Sheep abomasum. Coccidiosis. A giant round thick-walled schizont (arrow) in the mucosa surrounded by inflammatory cells. Bar $=1$ $\mathrm{cm}$.

\section{DISCUSSION}

In the present study, ostertagiosis was the most common lesion in the abomasa. In temperate climatic zones throughout the world, ostertagiosis is considered probably the most important parasitic disease in grazing sheep and cattle (Gelberg, 2011). In ostertagiosis, the multinodular or cobblestone appearance of abomasum is due to enlargement of the gastric glands because of mucous cell hyperplasia and hyperplasia of lymphoid nodules in the submucosa elevating the overlying mucosa (Gelberg, 2011). Concurrent presence of the ulcers and small nodules of Ostertagia were observed in $61 \%$ of abomasa. Abomasal parasitic infections can increase the incidence of abomasal ulcers (Radostits et al., 2007).

In the present study, the prevalence of abomasal ulcers was 75 percent. On the basis of gross examination, the prevalence of abomasal ulcers in sheep is reported to be about $56.3 \%$, located mostly in the body of abomasum (Mostaghni, 1985). In cattle, of the 912 examined abomasa,
$20.5 \%$ had ulcerative lesions on the mucosa (Braun et al., 1991). In slaughtered water buffaloes, a relatively high prevalence about $63.5 \%$ type 1 abomasal ulcers was reported $(43 \%)$ which were subclassified as type 1a. Deeper injuries, type $1 \mathrm{~b}$, were observed in $31 \%$ of abomasa. Types $1 \mathrm{c}$ and $1 \mathrm{~d}$ were seen in $9.5 \%$ and $9 \%$, respectively (Ghadrdan-Mashhadi et $a l ., 2010)$. In ruminants, the etiology and pathogenesis of abomasal ulcers are reported to be similar to those of peptic ulcers in human beings (Smith et al., 1983).

In our study the prevalence of abomasal phytotrichobezoars was 12 percent. An annual prevalence of $1.95 \%$ abomasal phytobezoariasis in sheep from Urmia (northwestern Iran) has been reported (Azizi et al., 2010). The occurrence of abomasal phytobezoariasis in ruminants is rare, and usually occurs in the sporadic form (Sherman, 1981; Ravikumar et al., 1989; Sargison et al.. 1995). However, large numbers of sheep and goats could be affected simultaneously by the disease due to some particular management circumstances (Bath et al., 1992). Inflammation of the abomasa, manifested by leukocytic infiltration in the mucosal layer along with oedema, cystic changes of glands and glandular hyperplasia, could be due to either physical irritation caused by the bezoars as a foreign body or the effect of parasitic infestation of the abomasum causing similar lesions (Farshid et al., 2006). It has been well documented that chronic irritation of foreign bodies in the abomasum would bring about hyperplasia and hypertrophy of mucosal glands and is a defense mechanism against mechanical factors (Brown et al., 2007). The relationship between abomasal trichobezoars and perforating abomasal ulcers in unweaned beef calves has been investigated (Jelinski et al., 1996). Young ruminants are usually 
affected by rumen trichobezoariasis. The lack of roughage in diet, high stocking density, pruritis due to heavy mite or lice infestation, or some unknown dietary deficiency might be the cause of excessive ingestion of hair or wool in the young ruminants (Brown et al., 2007). These factors usually cause rumen trichobezoariasis. Phytobezoars are mainly formed in the abomasa. Abomasal phytobezoariasis are unlikely to cause apparent clinical signs unless the number and magnitude of the foreign bodies are severe (Radostits et al. 2007). Furthermore, pyloric obstruction or small intestinal (mostly duodenal and jejunal) obstruction could cause abdominal distention and colic due to phytobezoar movement during the sudden ration alteration to fresh wet roughages (Brown et al., 2007; Radostits et al., 2007).

In the present study, a small number of intact or degenerate schizonts of coccidia were observed in the upper and middle of mucosa, mostly in lacteals. Abomasal coccidiosis has been reported rarely in sheep. Recently, abomasal coccidiosis associated with proliferative abomasitis was reported in a sheep. In this case nodular-haemorrhagic mucosal lesions with hyperplasia of mucous neck cells and lymphoplasmacytic fibrosis of lamina propria associated with giant schizonts of uncertain taxonomy have been found (Maratea \& Miller, 2007). Microscopic features of the schizonts in our specimens were consistent with previous descriptions of Eimeria (Globidium) gilruthi. The distinctive lesions suggest that, similar to ostertagiasis, heavy coccidial infection of the abomasum should be considered as a cause of anorexia, diarrhoea, and proliferative abomasitis in sheep. Because only the schizont stage of E. gilruthi is known, the taxonomic status of the parasite is uncertain. Definitive identification of coccidian genera and species is based on morphologic characteristics of sporulated oocysts, including the number of sporocysts, distribution of sporozoites, size, shape, and appearance of the oocyst wall. The absence of oocysts and sexual tissue stages in the mucosa suggests that sheep may be abnormal hosts for this protozoan, with infections resulting in one or more generations of schizogony in the abomasum, but without progression to gametogony. Members of the genus Eimeria are normally highly host-specific, and cross-transmission between different host genera, including sheep and goats, is uncommon (Maratea \& Miller, 2007).

In conclusion, ostertagiosis was the most common abnormality in the abomasum of the sheep that can cause important economical losses. In addition, abomasal coccidiosis was reported for the first time in this region and further research is required to clarify the pathogenesis and its epidemiologic importance in sheep.

\section{REFERENCES}

Azizi, S., A. A. Farshid, K. Mardani \& H Farzaneh, 2010. Sheep abomasal phytobezoariasis: The effect of breed, season and age with histopathological observations. Iranian Journal of Veterinary Medicine, 4, 95-99.

Bath, G., P. Botha, H. Vorster \& R. Cross, 1992. Physical structure and chemical composition of abomasal phytobezoars of goats and sheep. Journal of the South African Veterinary Association, 63, 103-107.

Blowey, R., 2004. Bovine Medicine: Diseases and Husbandry of Cattle, ed. A. H. Andrews, Wiley-Blackwell, pp. 236-237.

Braun, U., R. Eicher \& F. Ehrensperger, 1991. Type 1 abomasal ulcers in dairy cattle. Journal of Veterinary Medicine, Series A, 38, 357-366. 
Brown, C. C., D. C. Baker \& I. K. Barker, 2007. Foreign bodies in the forestomachs. In: Jubb, Kennedy and Palmer's Pathology of Domestic Animals, ed M. G. Maxie, Saunders Elsevier, Edinburgh, pp. 44-45.

Cebra, C. K., S. J. Tornquist, R. J. Bildfell \& J. R. Heidel, 2003. Bile acids in gastric fluids from llamas and alpacas with and without ulcers. Journal of Veterinary Internal Medicine, 17, 567-570.

Farshid, A. A., S. Naem \& R. B. Alipour, 2006. Pathological changes of abomasum in naturally infected Makoyee sheep with Teladorsagia circumcincta. Pakistan Journal of Biological Sciences, 9, 2145-2148.

Gelberg, H. B. 2011. Alimentary system, In: Pathologic Basis of Veterinary Disease, $5^{\text {th }}$ edn, eds Zachary J. F. \& M. D. McGavin, Mosby Elsevier Inc., St. Louis, pp. 345-355.

Ghadrdan-Mashhadi, A., S. Esmaeilzadeh \& M. Gandomi, 2010. Prevalence of different abomasal ulcers in buffalos of Ahvaz: An abbatorial survey. Journal of Veterinary Research, 65, 351-356.

Gross, S., W. Ryan \& H. Ploeger, 1999. Anthelmintic treatment of dairy cows and its effect on milk production. The Veterinary Record, 144, 581-587.

Jelinski, M. D., C. S. Ribble, J. R. Campbell \& E. D. Janzen, 1996. Investigating the relationship between abomasal hairballs and perforating abomasal ulcers in unweaned beef calves. Canadian Veterinary Journal, 37, 23-26.

Maratea, K. A. \& M. A. Miller, 2007. Abomasal coccidiosis associated with proliferative abomasitis in a sheep. Journal of Veterinary Diagnostic Investigation, 19, 118-121.

Mostaghni, K., A. Hadjimohammadi \& K. Badiei, 2008. Reflux of duodenal bile acids and abomasal ulcerations in experimental abomasal displacement in sheep. Comparative Clinical Pathology, 17, 81-86.
Mostaghni, K., 1985. Prevalence of abomasal ulceration in sheep. Indian Journal of Animal Sciences, 55, 11-13.

Radostits, O. M., C. Gay, K. W. Hinchcliff \& P. D. Constable, 2007. Veterinary Medicine: A Textbook of the diseases of cattle, horses, sheep, pigs and goats. $10^{\text {th }}$ edn., Saunders, London, pp. 1548-1551.

Ravikumar, S., M. A. Najappa \& M. R. Gajendragad, 1989. Rare cases of phytobezoars in sheep. Indian Veterinary Journal, 66, 361-362.

Sargison, N., P. Scott \& K. Dun, 1995. Intestinal obstruction in a blue-faced Leicester ram associated with a phytobezoar lodged at the pelvic inlet. The Veterinary Record, 137, 222.

Sherman, D., 1981. Duodenal obstruction by a phytobezoar in goat. Journal of the American Veterinary Medical Association, 178, 139-140.

Smith, D. F., L. Munson \& H. N. Erb, 1983. Abomasal ulcer disease in adult dairy cattle. Cornell Veterinarian, 73, 213-224.

Whitlock, R., 1980. Bovine stomach diseases. In: Veterinary Gastroenterology, ed N. V. Anderson, Lea \& Febiger, Philadelphia, pp. 413-428.

Paper received 25.11.2013; accepted for publication 13.06.2014

\section{Correspondence:}

A. Khodakaram-Tafti

Department of Pathology,

School of Veterinary Medicine,

P. O. Box 71345-1731,

Shiraz University, Shiraz, Iran,

Tel.: +987116138600; fax: +987112286940, e-mail: tafti@shirazu.ac.ir 